\title{
ESPACIOS PÚBLICOS RECIENTEMENTE REMODELADOS EN EL CASCO ANTIGUO DE MADRID (2006-2011). LA PLAZA DE LAS CORTES Y LA PLAZA DEL CALLAO.
}

\author{
PUBLIC SPACE RECENTLY REMODELED IN THE OLD TOWN OF \\ MADRID (2006-2011). Las Cortes square and Callao square
}

\author{
Aurelio Nieto Codina ${ }^{1}$
}

Recibido: 30/04/ 2012

Aceptado: 12/06/2012

\begin{abstract}
Resumen: La descripción de las obras de renovación de dos plazas singulares del Casco Antiguo de Madrid (Plaza de Las Cortes y Plaza del Callao) sirve para ejemplificar los cambios recientes en las dinámicas de los espacios públicos urbanos, considerados como un patrimonio cultural vinculado a valores estéticos. Si tradicionalmente los valores cívicos y sociales definían a plazas, parques, jardines y calles, en esta nueva situación, se busca integrarlos en dinámicas empresariales, homogeneizando los diseños y entregándolos a intereses privados. El artículo comienza definiendo las claves que caracterizan a los espacios públicos urbanos y, tras revisar estudios recientes, presenta algunas alternativas metodológicas para analizarlos. PALABRAS CLAVE: Espacios públicos, patrimonio cultural, valores cívicos, plazas.

Abstract: The description of the renovation of two unique square in the Old Town of Madrid (Plaza de las Cortes and Plaza del Callao) serves to illustrate the recent changes in the dynamics of urban public spaces, considered as a cultural heritage linked with aesthetic values. If traditionally the social and civic values define squares, parks, gardens and streets, in this new situation, it will seek to integrate them into business dynamics, standardizing designs and turning them over to private interests. At first, the article defines key characteristics of urban public spaces and, after reviewing recentstudies, presents some methodological alternatives for analysis.

KEYWORDS: Public spaces, cultural heritage, civic values, squares.
\end{abstract}

"Nosotros también tenemos derecho a la belleza" (una abuela de favela, en Sao Paulo, Brasil).

\section{LAS DIFERENTES DIMENSIONES DEL ESPACIO PÚBLICO URBANO.}

Entre los elementos que configuran una ciudad, los espacios públicos han sido considerados habitualmente como el lugar ideal que encarna la dimensión más cívica de lo urbano ${ }^{2}$.

Los espacios públicos materializan en la ciudad lo abierto, se conforman como contenedores de actividades; lugares que permiten, al menos en teoría, la posibilidad de que todos los ciudadanos tengan acceso a unos bienes sociales de carácter intangible en términos de igualdad. En este sentido, cuando los espacios públicos sufren restricciones de cualquier índole las respuestas de los usuarios no se hacen esperar, y es que las plazas, parques, calles y jardines son el escenario más accesible para visualizar las acciones sociales, la esfera inmediata para hacer visible lo que se entiende por vida comunitaria. El espacio público es el contrapunto indispensable para nuestras acciones privadas, que tienen su lugar más reconocido en el espacio doméstico.

Aunque vivimos un momento ligado a nuevas realidades, tanto en lo que respecta a las formas de comunicación como a la presencia de mundos virtuales que llenan todos

ancodina@geo.uned.es.Profesor Asociado Departamento de Geografia. UNED

${ }^{2}$ Así se entiende por parte de J. Borja, quien insiste en la importancia de los espacios públicos como lugar privilegiado de socialización, estímulo para la identificación simbólica y medio para la integración cultural de sus habitantes (BORJA, 1998). 
los resquicios de la vida cotidiana, lo cierto es que los espacios públicos urbanos siguen siendo el marco privilegiado en que la ciudadanía visualiza y reivindica sus derechos. Si una acción social pretende de alguna manera tener una cierta trascendencia en la conciencia colectiva, no puede prescindir de su presencia en el espacio público ${ }^{3}$.

La variedad de formas del espacio público urbano determina la diversidad de usos, la capacidad de integración en ellos de las actividades de los ciudadanos y la riqueza simbólico - visual que define una ciudad. Todos estos aspectos inciden en dar cuerpo a lo que Kevin Lynch Ilamaba la imagen de la ciudad (LYNCH, 1959). En este sentido, los espacios públicos se pueden considerar como un patrimonio cultural, una propiedad de todos los ciudadanos. Para entender este aspecto en toda su dimensión debemos incluir en él no sólo la forma y extensión de calles, parques, jardines y plazas, sino también sus componentes arquitectónicos (fachadas y alzados de edificios), su vegetación, sus pavimentos y su mobiliario urbano (MARTíNEZ SARANDESES, 1990). Si tomamos conciencia del valor patrimonial de los espacios públicos y de su importancia como medio de expresión colectiva, podemos entender que cualquier modificación de los mismos implica unas consecuencias de alto calado ya que afectan a todos los ciudadanos; por tanto, cualquier alteración de los mismos puede ser evaluada tanto por las consecuencias positivas como por las negativas. Es evidente que cualquier alteración del espacio público modifica los comportamientos de los usuarios y, en este sentido, según el grado de visibilidad del mismo en el grueso de la población, el impacto del cambio será más o menos importante, tanto en términos de funcionalidad como en el ámbito de lo simbólico. No se descubre nada nuevo si se dice que una modificación de plazas o jardines en el centro histórico tiene un impacto mediático más fuerte que si se realiza en un barrio residencial periférico. Si que creo que se debe insistir, en relación con la cita que abre este artículo, en la importancia de la dimensión estética del espacio público: un conjunto de lugares que no sólo posibilitan la realización de actividades, sino que también actúan en la conciencia de los ciudadanos como lugares agradables a disposición de todos, como una oportunidad de uso con independencia o no de que se ejerza dicha posibilidad (SABLET, 1988). Así, la dimensión estética de plazas, parques y determinadas calles es una fuente de disfrute visual inmediato para muchos ciudadanos, incluso para algunos grupos sociales esta es la única opción de acceso a lo "bello». Tener este aspecto presente implica cuidar con especial atención las dotaciones que se instalan en el espacio público, sobre todo teniendo en cuenta que se trata de inversiones que no es factible renovar en cortos espacios de tiempo.

Los espacios públicos, en su sentido más amplio, contribuyen a la construcción de la ciudad en el sentido materia y simbólico; en realidad funcionan como nodos que articulan los encuentros personales y las diferentes posibilidades de actividad callejera. Este aspecto es el que está siendo más explotado en las ciudades actuales, sobre todo en los centros históricos que se renuevan, y así incrementan su potencialidad como lugares de dinamización del conjunto de la ciudad (GAVENTA, 2006). En este sentido, el incremento del turismo urbano $y$, sobre todo, la sobreacumulación de visitantes y transeúntes en los espacios libres de los cascos antiguos de las grandes ciudades, son indicios del importante papel de los mismos dentro de la trama urbana, no sólo como elementos articuladores, también como lugares emblemáticos y como ámbitos clave de la dimensión simbólica de la ciudad (HARVEY, 2003).

Aunque en el presente texto, como ejemplos prácticos, sólo se describe la renovación urbanística de dos plazas concretas del Casco Antiguo de Madrid, es conveniente insistir previamente en la complejidad metodológica del estudio de los espacios públicos y, también, en el impacto que este tipo de renovaciones (muy frecuentes en numerosas ciudades actuales de todo el mundo ${ }^{4}$ ) provocan en la imagen tradicional que los ciudadanos tienen de los espacios públicos urbanos.

\section{LA COMPLEJA REALIDAD DEL ESPACIO PÚBLICO. ALGUNAS PROPUESTAS PARA SU ANÁLISIS.}

Los estudios de calidad de vida urbana no se pueden abordar dejando al margen los espacios públicos; de igual modo, planificadores y poderes municipales tampoco pueden olvidar en sus proyectos todas las dimensiones que configuran los espacios públicos.

Desde este contexto, las metodologías y los criterios empleados para el estudio de los espacios públicos deben plantearse desde posturas novedosas, que no marginen ningún aspecto y que sepan coordinar los planteamientos propios de una opción multidisciplinar, en este terreno la geografía tiene que encontrar su propio acomodo. La manera más inmediata de enfrentarse al estudio de los espacios públicos urbanos deriva del trabajo de arquitectos y urbanistas (ASHIHARA, 1983; CULLEN, 1974; MARTÍNEZ SARANDESES, et $a l, 1990)$, normalmente estos trabajos pormenorizan un ca-

\footnotetext{
3 A pesar que desde los medios de comunicación se insiste, con razón, en la importancia de las redes sociales y de Internet en muchos de los procesos reivindicativos de carácter social desarrollados recientemente (el movimiento 15M en España o la primavera árabe de 2012), lo cierto es que hasta que estas formas de protesta no "toman la calle» no adquieren un reconocimiento mayoritario. Cualquier movimiento social necesita para su dimensión simbólica tener presencia en un espacio público.

${ }^{4}$ Algunos ejemplos de renovaciones recientes de espacios públicos en GAVENTA, 2006.
} 
tálogo de disfuncionalidades y patologías del espacio público en relación al diseño, la ejecución, el emplazamiento y el mantenimiento de plazas, parques y calles.

Otros estudios más complejos, parten de la elaboración de matrices analíticas en las que se busca un diagnóstico más preciso de los sistemas locales de espacios públicos (GARCÍA GARCÍA, 2011). Estos análisis espaciales van asociados a la caracterización de las densidades de viviendas, a la comprensión de las relaciones de cada lugar dentro de un sistema de espacios libres y, además, valoran el comportamiento de los usuarios en los mismos. Partiendo del citado estudio se pueden establecer tres categorias conceptuales:

La red de espacios públicos de una ciudad como un conjunto de huecos, de lugares libres de edificación que para su cabal comprensión, para su empleo como fuente de hipótesis de trabajo, necesita de la elaboración de un inventario de estos espacios en base a una cartografía de los mismos. En relación con las metodologías que estamos sintetizando es evidente que este aspecto ofrece sólo una dimensión parcial de todos los problemas que se asocian a nuestro tema.

La segunda opción es considerar el conjunto de espacios públicas como estándar urbanístico, se trata de una consideración cuantitativa, esta metodología entiende el espacio público como dotación residencial, como un equipamiento que se valora en relación a su accesibilidad, qué distancia hay que recorrer hasta llegar a él y qué porcentaje hay en cada barrio en relación a la densidad residencial. Se puede definir como análisis de accesibilidad, normalmente una visión de la ciudad cercana a la de los planificadores funcionalistas. Esta manera de enfocar los espacios públicos no tiene en cuenta la calidad de los mismos, solo su número, no se preocupa por ejemplo de la vegetación, el mobiliario urbano y otros elementos que definen la calidad en estos ámbitos.

Sin ignorar las metodologías anteriores, lo cierto es que no se pueden entender plenamente los espacios públicos si no se comprenden como escenarios de la experiencia urbana (SABLET, 1988). Entender las redes urbanas de espacios libres desde una perspectiva cualitativa es, sobre todo, diferenciarlas de otro tipo de dotaciones o equipamientos que son más susceptibles de cuantificar, como los sanitarios 0 los educativos. Los espacios públicos deben entenderse bajo diversas condiciones: su ubicación en la trama urbana, su accesibilidad, sus contenidos dotacionales en relación a las diversas necesidades de los usuarios y, por último, su grado de participación en la consecución de unos niveles óptimos de sociabilidad en la ciudad 5 .

Los tres aspectos expresados anteriormente son en realidad tres escalones en un proceso de búsqueda, un intento de alcanzar un entendimiento pleno de los espacios públicos urbanos. Primero, partiendo de su realidad física expresada de manera visual (cartográfica) como elementos dentro de un conjunto; en un segundo paso, estableciendo unos valores porcentuales que determinan su presencia óptima en un entorno concreto (estándar urbanístico), sin olvidar que estos valores siempre deben considerarse como mínimos no como objetivo a lograr; por último, descubriendo la carga existencial de estos espacios (valores cualitativos), tratar de entenderlos como escenarios en los que los ciudadanos satisfacen unas necesidades de tipo social.

\section{RENOVACIÓN DE LOS ESPACIOS PÚBLI- COS URBANOS Y ALTERACIÓN RADICAL DE SUS VALORES SOCIALES.}

La importancia creciente para planificadores y estudiosos de los espacios públicos se pone de manifiesto en el refinamiento de las metodologías, tal y como han sido expresadas en el apartado anterior. Pero este progreso en la definición teórica no ha supuesto una mejora general en la remodelación real de los espacios públicos, tal y como se ve en los dos ejemplos seleccionados de intervención radical en el Casco Antiguo de Madrid.

Los espacios públicos tradicionales contribuían a una polivalencia de la funcionalidad, al tiempo que no descuidaban los aspectos estéticos (MARTíNEZ SARANDESES, 1990). Muchos factores se imbricaban para lograr estos objetivos; el diseño, la accesibilidad, la belleza, la monumentalidad, el mantenimiento, la diversidad de usuarios posibles, etc. Se ha señalado con acierto, que "el lujo del espacio público no es despilfarro, es una cuestión de justicia socialı (BORJA, 1998).

El interés creciente de los poderes municipales por remodelar el espacio público es un fenómeno mundial, en muchas ocasiones con presupuestos de dimensiones millonarias como el Millennium Park de Chicago o el Westblaak Skatepark in Rotterdam (CARMONA, 2003). En estos proyectos artistas, arquitectos, diseñadores y autoridades locales entran en un complejo juego de relaciones que moviliza amplios recursos financieros. En los ejemplos madrileños, la escala de actuación es más modesta, pero la dinámica a la que responden es la misma. Se trata de una tendencia mundial que lleva a las ciudades a participar de un nivel de competitividad encaminado a captar inversiones y turismo, y para ello es imprescindible cambiar la imagen de los espacios públicos para que sean más atractivos como productos destinados al mercado, aunque en contrapartida se comprometan los valores sociales tradicionales de unos espacios que tenían como objetivo servir a la comunidad.

5 No se puede olvidar que las intervenciones en el tejido urbano suponen siempre una alteración de los usos sociales del espacio, y como investigadores debemos siempre tener presente a que intereses responden las "renovaciones urbanas», a este respecto es ejemplar el posicionamiento teórico de personalidades que como Jane Jacobs aún nos pueden servir de guías (JACOBS, 1967). 
La economía neoliberal ha generado una industria nueva que todo lo integra en el mercado, nada queda fuera de su influencia, el espacio se transforma en su integridad para generar nuevas realidades urbanas regidas por un interés mercantil, cada vez más alejadas de los valores sociales (LEFEBVRE, 1976).

Este concepto ha sido desarrollado también por geógrafos marxistas como David Harvey, quien en relación con la renovación de los espacios públicos ha acuñado el término utopía degenerada de la ciudad (HARVEY, 2003). Se refiere a la ciudad como utopía sobre la que se proyectan una serie de deseos que la transforman pero en un sentido negativo, la ciudad como un espectáculo que la acaba convirtiendo en mercancía, los espacios transformados con este objetivo se venden por los medios de comunicación como resultado de una necesidad del progreso. La ideología y las prácticas neoliberales competitivas hacen su trabajo silenciosamente imponiendo una corrección política que impide la existencia de una auténtica opinión pública al respecto, así las inversiones que potencian el consumo y el turismo se ven como una panacea con independencia de las exigencias que imponen al conjunto de los ciudadanos. Según estos principios se crean escenarios ideales para el consumismo en los que el ocio genera símbolos que son reconocidos internacionalmente; cafeterías, tiendas de moda, edificios comerciales multinacionales, etc. Como complemento a estos cambios, las plazas y calles se deben acondicionar en función de los intereses de estos negocios.

A propósito de estas nuevas actuaciones urbanísticas, resulta significativo el cambio sufrido por el frente marítimo de A Coruña (SANZ FREIRE, 2006), un conjunto renovado que ejemplifica los cambios sufridos por otros cascos históricos. En este caso, se detecta un abandono del tratamiento integral del centro histórico a favor de intervenciones muy loca- lizadas (Palacio de Congresos y paseos marítimos) que favorecen un vaciado de los contenidos cívicos, una reducción de la diversidad ambiental, y una orientación funcional casi exclusiva privilegiando un área de ocio urbano de tipo estándar, similar a los encontrados en otros lugares del mundo.

\section{DOS EJEMPLOS DE PLAZAS REMODELA- DAS EN EL CASCO ANTIGUO DE MA- DRID}

En el Casco Antiguo madrileño también aparecen ejemplos de remodelaciones que buscan crear espacios homogeneizados, según unos criterios reconocidos a nivel mundial que potencian el consumo, la reducción funcional al servicio de intereses empresariales y la aparición de elementos que actualizan la presencia de la publicidad en plazas y calles. Se trata de unos espacios heredados que se transforman y generan unas nuevas imágenes más anodinas que las tradicionales.

\subsection{La plaza de las Cortes}

Esta plaza está muy condicionada tanto por su particular topografía, con una pendiente muy acusada, como por ser antesala del Palacio del Congreso de los Diputados.

En 1860 se realizó la primera remodelación importante de este espacio, un proyecto que elaboró nada menos que Carlos María de Castro, el artífice del Ensanche de Madrid. Se trata en el caso de esta plaza de una obra inspirada en los square ingleses, un modelo de plaza pública entonces muy difundido por toda Europa que utiliza pavimentos de tierra apisonada (macadam), presenta un uso generoso de la vegetación arbórea y arbustiva, bancos diseminados irregularmente en torno a un punto central y cierres del espacio con

FIGURA 1. La plaza de las Cortes antes de la remodelación de 2006.

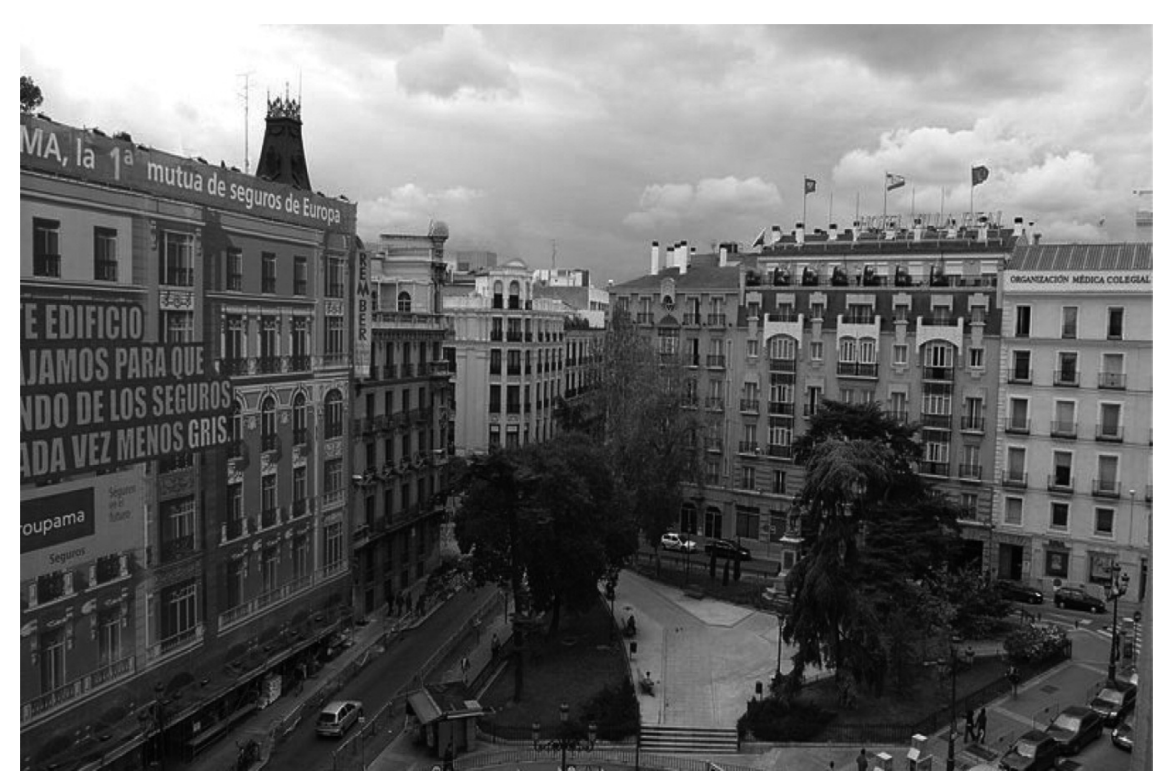

Fuente: http://www.flickr.com/photos/seisdeagosto/139950824/ 
enrejados de forja. Esta estructura, con cambios más o menos circunstanciales, era la que se mantenía hasta la remodelación reciente.

El proyecto de Castro se planteó con un presupuesto de 29630,60 reales, una cantidad que en su época se consideró poco elevada y ahorrativa. Se diseñaron en su momento dieciocho asientos con estructura de fundición y superficies de madera y diez candelabros a modo de iluminación; todo el conjunto, tanto en estructura como en lo que a dotaciones se refiere, fue pensado como una prolongación de los jardines del paseo del Prado. Los bancos rodeaban la estatua central de Cervantes, que aparece ataviado como militar y que es una de las estatuas más antiguas del patrimonio artístico madrileño al aire libre. Los bancos, según Castro, se pensaron "para que las personas tengan un lugar donde reposar las fatigas que les produzca la pendiente de la calle» ${ }^{6}$. Es así que se cumplía uno de los tres propósitos típicos del urbanismo tradicional en lo que al espacio público se refiere: comodidad, belleza y perdurabilidad.

En el plano que se adjunta al proyecto, conservado en el Archivo de la Villa de Madrid, también diseñó Castro las típicas casetas para los guardas que protegían los jardines públicos, una costumbre y un tipo de microarquitectura que han desaparecido de nuestras ciudades.

En la figura 1, se muestra el aspecto de la plaza previo al inicio de las obras de remodelación. Se observa su planta poligonal adaptada al desnivel que se salva con unos discretos escalones, se mantiene la generosidad en la presencia de vegetación. En 2006 se conservaban las rejas de la época de Castro, aunque la estatua ya había perdido su posición céntrica adelantada al extremo superior. En el extremo inferior de la plaza existía un quiosco de periódicos.

El 9 de mayo de 2006 se presenta en el Ayuntamiento de Madrid la documentación del proyecto de nueva plaza diseñado por el equipo del arquitecto portugués Alvaro Siza, con el que colaboran Juan Miguel Hernandez León, Carlos de Riaño, Jose Miguel Rueda y Fernando de Terán ${ }^{7}$. Al igual que en los tiempos de Castro, la plaza es parte de una idea más amplia que engloba a ésta dentro del diseño de los paseos del Prado y Recoletos. Hasta ahí las coincidencias, pues todo lo demás es radicalmente nuevo.

A partir de la figura 2, podemos deducir dos características del nuevo diseño de plazas y una específica de la plaza de Las Cortes:

- Reducción de la vegetación que aparece limitada a elementos arbóreos, desaparecen las terrizas y con ella el césped y los arbustos.

- Enlosados de granito, siguiendo una tendencia general en Madrid que pretende la impermeabilización total de la ciudad, sin resquicio para la arena, que es incluso cubierta con materiales sintéticos en los alcorques de los árboles.

- Eliminación del enrejado de forja que delimitaba la plaza, ahora todo es un continuo sin limitaciones unificando la plaza con las calles aledañas, destacan las losas de granito muy del gusto de Siza, a modo de (incómodos) asientos.

FIGURA 2. Plaza de las Cortes remodelada

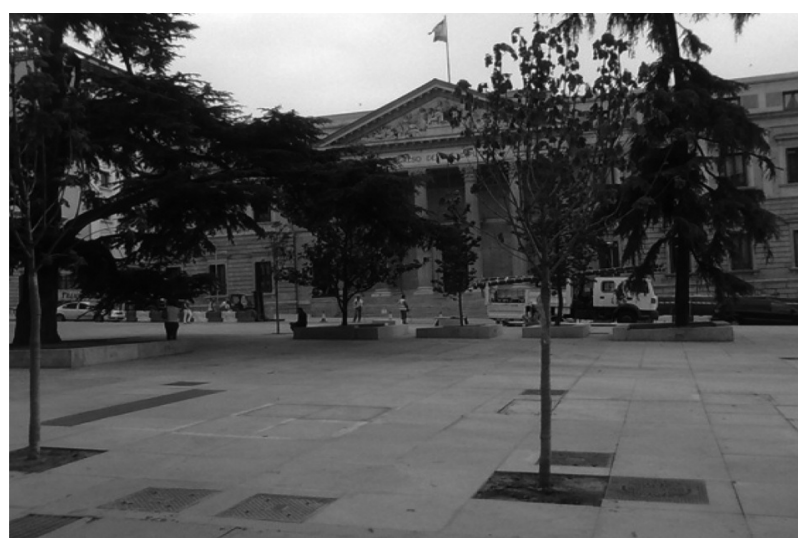

Fuente: www.espormadrid.es/2010/

La intervención provoca al poco de su inauguración una disfuncionalidad no pensada por los responsables del proyecto, el desnivel tradicional de la plaza se ha salvado con unos desafortunados escalones de inmensa huella, que para ser sorteados necesitan que el peatón realice una gran zancada (figura 3). Un inconveniente para amplios grupos de población (niños, ancianos, discapacitados) que ven alterada la posibilidad de atravesar la plaza cómodamente. En un primer momento el descabellado desnivel hizo las delicias de los skaters que con sus patinetas realizaban acrobáticos saltos, un ejemplo de cómo un mismo espacio es entendido de manera diferente por los distintos grupos de personas.

FIGURA 3. Plaza de las Cortes. Desnivel mal resuelto urbanísticamente

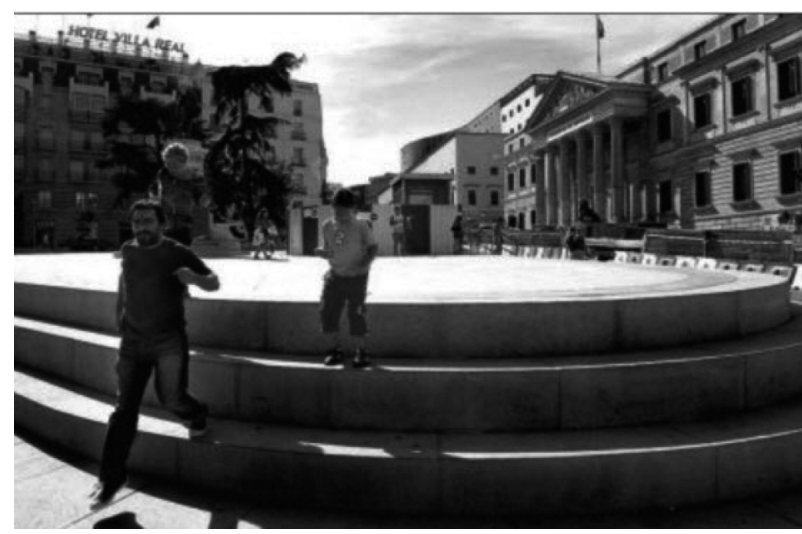

Fuente: www.espormadrid.es/2010/

${ }^{6}$ Archivo de Villa (AV), Madrid, Sección Secretaría, legajo 4-227-70.

${ }^{7}$ Ayuntamiento de Madrid, Gerencia Municipal de Urbanismo, 9/05/2012. Área de Gobierno de Urbanismo y vivienda. 
FIGURA 4. Maceteros como barrera urbanística.

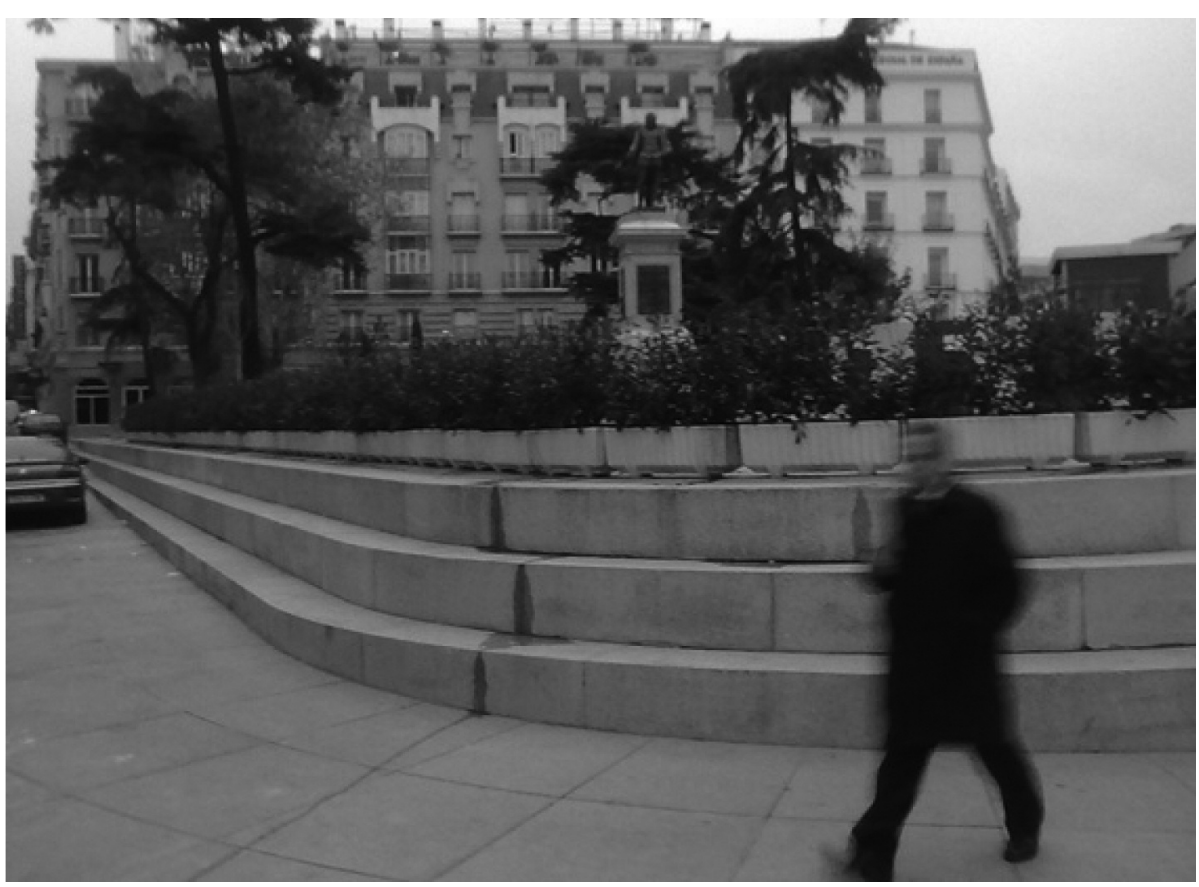

Fuente: www.espormadrid.es/2010/

Los "expertos" del urbanismo municipal deciden ante esta situación rodear la plaza de unas jardineras estándar, que impiden las acrobacias y protegen a los peatones de posibles accidentes ante el descomunal salto de nivel. El nuevo problema deriva del riego de los maceteros, ya que en el diseño original no se contemplaba esta opción, es por ello que surgen dificultades para el drenaje, molestas en una plaza bastante concurrida.

La nueva plaza de las Cortes ha perdido su fisonomía tradicional a favor de una homogeneidad coincidente con gran parte de las plazas del Casco Antiguo. En este sentido ha perdido su personalidad casi por entero. Los árboles han quedado individualizados de manera ostentosa y ya no es un espacio que llame al descanso, pues la sensación de apertura al entorno resta tranquilidad. Todo es demasiado duro, como en los cuadros de Giorgio de Chirico, sólo la estatua cervantina nos recuerda que se trata de una plaza con valores históricos. Con independencia de los gustos estéticos de cada observador, lo cierto es que la remodelación de las plazas lo primero que ha provocado es una disfuncionalidad derivada de la errónea solución planteada para salvar la diferencia de nivel.

\subsection{La plaza del Callao}

Al contrario que la plaza de las Cortes, la plaza del CaIlao no contaba con elementos relevantes de tipo artístico o medioambiental, tanto su estructura, como el mobiliario o la vegetación no precisaban de ningún grado de protección urbanistica.
La evolución de la plaza desde el siglo XIX y sus cambios en relación a la reforma de la Gran Vía ha sido ya ampliamente descrita (JIMÉNEZ, 1977, pp. 45 y 46). La situación previa a 2006 era fruto de una remodelación de los años ochenta. La plaza, de forma semicircular, tenía una gran isleta central con las salidas del metro, quiosco de prensa, bancos, farolas, una fuente, jarrones decorativos neobarrocos, vegetación arbustiva y arbórea. El rectángulo central estaba rodeado de viales para el tráfico de vehículos y pasos de peatones.

La remodelación de la plaza del Callao como cualquier intervención en tejido urbano consolidado se enfrenta al dilema siguiente, ¿Qué tipo de intervención es mejor, la conservación estricta de lo preexistente, la rehabilitación o la renovación total? En el caso de la plaza de las Cortes, un lugar con valores urbanísticos heredados y con un gran urbanista detrás del proyecto decimonónico, Carlos M. de Castro, hubiera sido deseable una intervención menos radical, más sensible a los valores existentes, sin pretender su conservación museística, pero sí con una mirada más respetuosa y más preocupada por mantener la funcionalidad previa de la plaza.

En el caso de la plaza del Callao, la situación de base era diferente, ya que no había elementos relevantes que preservar, aunque tampoco ha habido una preocupación por analizar los usos y actividades que los ciudadanos hacian de la plaza antes de la intervención. Tanto en un caso como en otro, las dos actuaciones están dictadas por una de las figuras del planeamiento creadas para controlar las intervencio- 
nes en el espacio urbano consolidado: el plan especial (PESanto Domingo-Callao, figura 5).

Desde los planteamientos teóricos de la planificación, los planes especiales se realizan en principio con el objetivo de obtener una mejora de las dotaciones de los espacios públicos urbanos consolidados, deben además contemplar siempre la recuperación o rehabilitación de los valores históricos y la mejora de las condiciones medioambientales, tal y como es descrito por L. Moya ${ }^{8}$. No parece que estos criterios hayan guiado ninguna de las dos actuaciones urbanísticas. En el caso de la plaza del Callao, incluida dentro de un PE que también modifica la plaza de Santo Domingo y cinco calles del entorno (figura 5), el criterio urbanístico ha sido bien simple: arrasar todos los elementos preexistentes, a excepción de un árbol de gran porte y la salida del metro, y unificar todos los pavimentos con losas de granito para que el conjunto de calles y plaza sean peatonales manteniendo como límite la Gran Vía. Respecto al escaso mobiliario urbano, se alinean tres nuevos quioscos utilizando como referencia la bella fachada art decó del cine Callao. La creación de un gran espacio homogéneo a modo de plaza dura hace tabula rasa de los usos preexistentes de la plaza (figura 6), ya que la "limpieza» de los elementos previos tiene un objetivo muy preciso: utilizar la plaza para eventos de prestigio (estrenos de cine, desfiles y pasarelas de moda, expositores de marcas de lujo, promociones comerciales, etc.) y alquilarla en función del ocio estacional (pistas de hielo, patinaje, jue- gos infantiles). Es decir, se favorece la privatización de un espacio singular para actividades empresariales diversas, al tiempo que se socializa el gasto para acondicionar una plaza que pierde parte de su función cívica. Es cierto, que la plaza a partir de ahora generará recursos financieros a las arcas municipales, pero a costa de alterar física, simbólica y funcionalmente una de las plazas más transitadas del Madrid antiguo.

El planteamiento desarrollado en este artículo no coincide con la publicidad institucional, para el Ayuntamiento de Madrid "la rehabilitación, la plaza, cobra una dimensión más humana, al haber sido diseñada para devolver al peatón nuevos espaciosı' ${ }^{9}$. Después de 2006 (figura 7), el espacio reestructurado entre la plaza de Callao y las calles de su entorno -Jacometrezo, Cuesta de Santo Domingo, San Bernardo y Silva-, las superficies peatonales han crecido en más del $60 \%$, pasando de 7.780 a 12.520 metros cuadrados. Entre las nuevas funciones creadas en la plaza remodelada, destaca la que deriva de las grandes pantallas instaladas en las fachadas del cine Callao; la calle a modo de escenario que proyecta publicidad enmascarada entre información de tipo cultural. Las pantallas son tal vez el elemento más evidente de la entrega de los espacios públicos a intereses privados, no por transmitir imágenes, sino porque éstas son casi en exclusiva referidas a publicidad.

Las pantallas en el centro histórico copian una idea que se experimentó hace décadas en Nueva York y Londres.

FIGURA 5. Imagen oficial del Plan Especial «Santo Domingo-Callao»

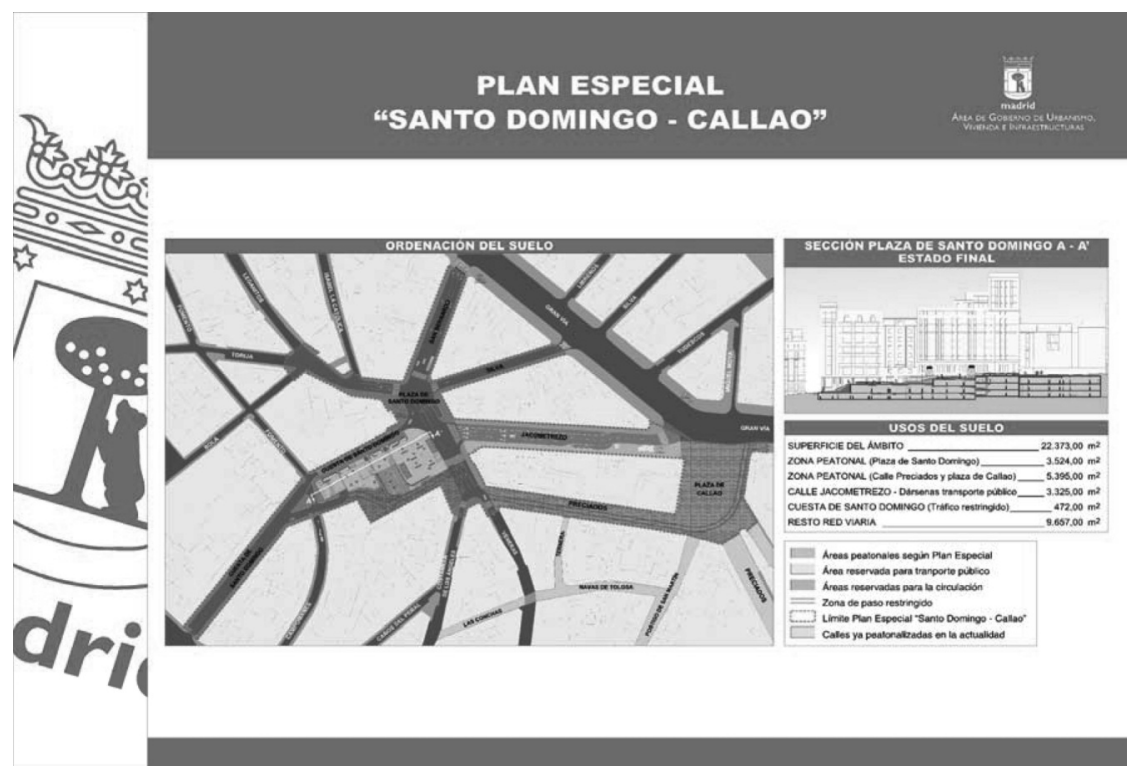

Fuente: Ayuntamiento de Madrid, Área de Gobierno de Urbanismo y Vivienda

${ }^{8}$ La tendencia de los años ochenta del siglo XX a sustituir radicalmente vegetación y mobiliario urbano, parece que continúa a comienzas del siglo XXI. Sobre los cambios en relación a la definición de lo que implican los planes especiales, véase: MOYA, 1994, pp. 227 y 229.

${ }^{9}$ Información del Ayuntamiento de Madrid, Área de Gobierno de Urbanismo y Vivienda. www.madrid.es. 
Figura 6. Plaza del Callao antes de 2006.

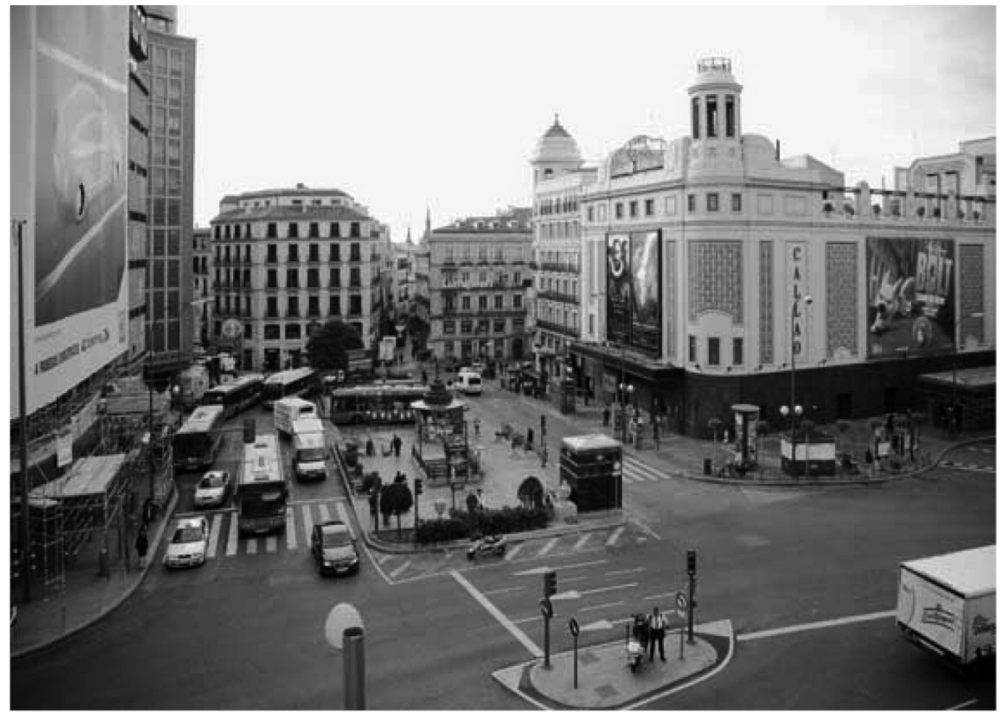

Fuente: www.madrid.es/portales/munimadrid

\section{CONCLUSIÓN}

Las dos plazas son representativas de una dinámica de renovación de los espacios públicos que tiene una dimensión local y otra internacional. Con respecto al contexto madrileño, se pueden incluir dentro de una tendencia nacida a finales del siglo XX, plenamente desarrollada entre 2003 y 2011 (años del gobierno municipal de derechas de Alberto Ruiz Gallardón), caracterizada por la sustitución de terrizas y alcorques a favor de la impermeabilización total básicamente con el empleo de losas de granito. Las plazas y calles se convierten así en un continuo peatonal libre y diáfano que en su mayor parte no presenta objetos o los limita a zonas marginales, reduciendo la presencia de vegetación y mobiliario urbano para favorecer espacios amplios, fácilmente explotables mediante instalaciones comerciales (terrazas, infraestructuras de ocio, publicidad, etc.) y disponibles para eventos de tipo privado.

A nivel internacional, es evidente que la mayoría de las recientes actuaciones sobre espacios públicos significativos y céntricos tratan de convertir la ciudad en una nueva forma de espectáculo (utilizando la terminología de teóricos como

Figura 7. La plaza del Callao después de 2006

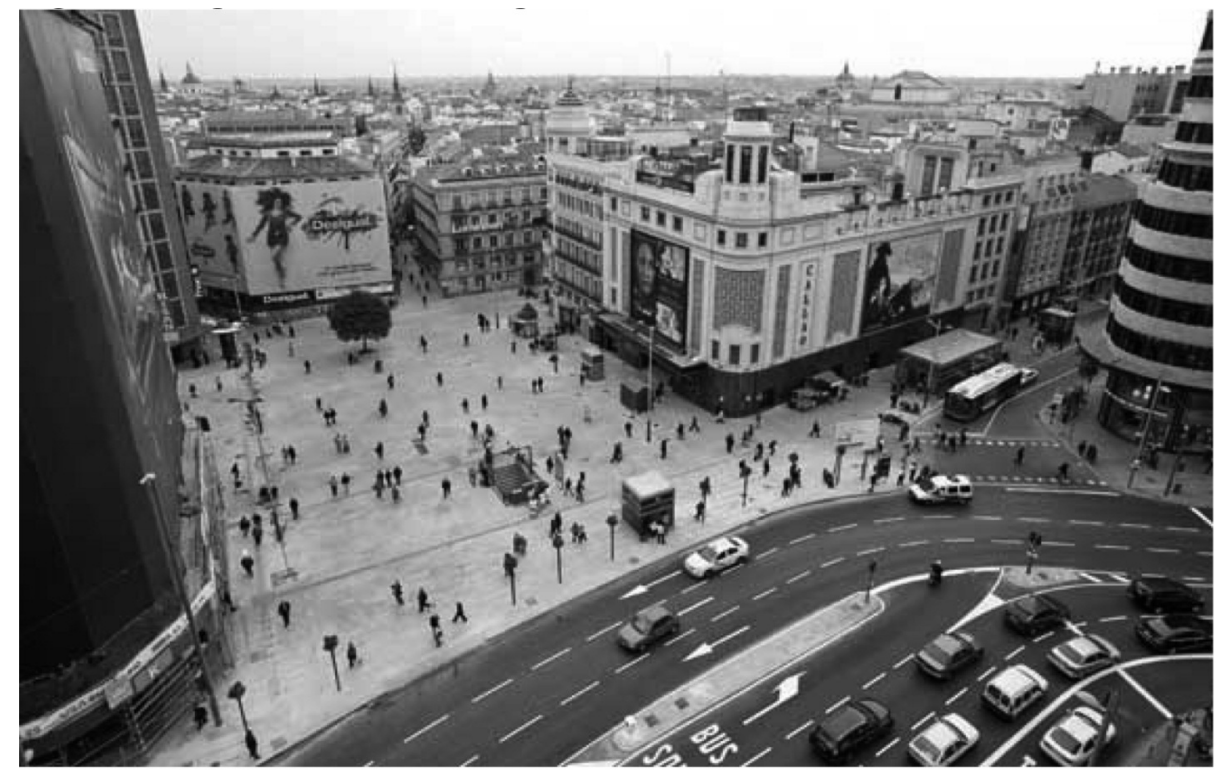

Fuente: www.madrid.es/portales/munimadrid 
Harvey), fácil de comercializar en función del turismo y con un amplio margen para gestionar un nuevo tipo de imágenes que sirvan para atraer inversiones, aunque sea a costa de reducir los valores cívicos del entorno cotidiano. En este contexto, los usuarios se entienden más como consumidores que como ciudadanos, sus opiniones y sus comportamientos se tratan de canalizar hacia la aceptación acrítica del entorno urbano. Estos nuevos espacios, cada vez más carentes de contenido social y amparados en la esfera de lo empresarial, comienzan a ser equiparables a lo que Marc Augé denominó "no lugares", un término que en principio se pensó para autopistas, supermercados, aeropuertos, etc. (AUGÉ, 1992), pero que ahora parece que es extrapolable a otras realidades urbanas.

Materialmente, las nuevas plazas madrileñas del centro histórico se definen sobre todo por sus enlosados y empedrados costosos, bancos simplistas, farolas anodinas, sin criterios estéticos de jardinería y un amueblamiento de muy baja calidad estética.

La mejora de la calidad ambiental sólo es relativa, sí es cierto que se reduce la presencia de automóviles en las zonas de actuación, pero no se incrementa la presencia de elementos naturales, estéticos o de cualquier otra índole, diseñados para lograr una mejora del confort climático.

Lo cierto es que los espacios públicos de las ciudades históricas son un tipo de patrimonio cultural a menudo ignorado o menospreciado ${ }^{10}$, si se comparan con el cuidado y la protección prestada a monumentos, yacimientos arqueológicos y museos. Las actuaciones urbanísticas desarrolladas entre 2006 y 2011 en las plazas madrileñas suponen una pérdida sustancial de valores patrimoniales. Es cierto que no se destruyen obras singulares excepcionales pero sí se atacan valores relacionados con la preservación del paisaje histórico de las ciudades entendidas como conjunto. Esta situación deriva en principio de la imposición de valores empresariales, pero hay más circunstancias que contribuyen a alimentar esta dinámica negativa: la falta de sensibilidad de los poderes públicos y la escasa concienciación de los ciudadanos a este respecto.

Es sorprendente también el escaso impacto reivindicativo de los especialistas en esta materia (diseñadores, arquitectos, investigadores, etc), que deberian haber actuado como conciencia crítica más activa ante las transformaciones radicales del entorno urbano.

\section{BIBLIOGRAFÍA}

ASHIHARA, Y. (1983). El diseño de espacios exteriores, Barcelona, Gustavo Gili.

AUGÉ, M. (1992). Los «no lugares», espacios del anonimato. Una antropología de la sobremodernidad, Barcelona, Gedisa.

BORJA, J. (1998). "Ciudadanía y espacio público», en: Urbanitat: Ciutat real, ciutat ideal. Significat i funció a l'espai urbà modern, BarceIona, CCCB. Disponible:<http://urban.cccb.org/urbanLibrary/ htmIDbDocs/A011-B.html>. Obtenido en 15 de abril de 2012.

BUSTILLOS BRAVO, I.; LASHERAS MERINO, C.; MARTÍN MORATALLA, M. (1985). Espacios públicos en el Casco Histórico de Madrid. Tipos, configuración y génesis, Ayuntamiento de Madrid, Madrid.

CARMONA, M.; HEATH, T.; TIESDELL, S. (2003). Public places, urban spaces. The Dimensions of Urban Design, Oxford, Architectural Press.

CULLEN, G. (1974). El paisaje urbano. Tratado de estética urbanistica, Blume, Barcelona.

FERNÁNDEZ PARDO, F. (2007). Dispersión y destrucción del patrimonio artístico español, Madrid, Fundación Universitaria Española.

GARCÍA GARCÍA, A. (2006). Vitalidad y crisis en los espacios públicos de Sevilla, Sevilla, Diputación de Sevilla.

GARCÍA GARCÍA, A. (2011). «El valor de la perspectiva geográfica para el análisis de los espacios públicos urbano", Boletín de la Asociación de Geógrafos Españoles, 55, pp. 281 - 301.

GAVENTA, S. (2006). New Public Spaces, Londres, Mirchel Beazley Press. HARVEY, D. (2003). Espacios de esperanza, Madrid, Akal.

JIMÉNEZ, M. (1977). Madrid en sus plazas, parques y jardines. Madrid, Ábaco.

JACOBS, J. (1967). Muerte y vida de las grandes ciudades, Madrid, Península.

LEFEBVRE, H. (1976). Espacio y politica. El derecho a la ciudad, BarceIona, Península.

LYNCH, K. (1959). La imagen de la ciudad, Buenos Aires, Infinito.

MARTINEZ SARANDESES, J.; HERRERO MOLINA, M.; MEDINA MURO, M. (1990). Espacios públicos urbanos: trazado, urbanización y mantenimiento, M.O.P.U., Madrid.

MOYA, L. (1994). La práctica del planeamiento urbanistico, Madrid, Síntesis.

SABLET, M. de (1988). Des espaces urbains agréables a vivre. Places, rues, squares et jardins, Editions du Moniteur, Paris.

SÁNCHEZ QUIRANTE, L. (2003). "La contaminación visual en Baza: un problema de difícil solución”, Jornadas de Contaminación Visual del Patrimonio Histórico en Andalucía, Junta de Andalucia, Sevilla, p. 93 y ss.

SANZ FREIRE, R. (2006). «La destrucción del paisaje urbano en el Casco Histórico de A Coruñan, Biblio 3W. Revista bibliográfica de geografía y ciencias sociales (Serie documental de Geo Crítica), 682, 9 pp. 
